\section{FORMAÇÃO DE JOGADORES EM CLUBES DE UMA CIDADE DO INTERIOR: CIRCULAÇÃO, ESCOLARIZAÇÃO E INSERÇÃO NO FUTEBOL PROFISSIONAL}

\author{
FORMATION OF PLAYERS IN CLUBS OF A BRAZILIAN CITY: CIRCULATION, \\ SCHOOLING AND INCLUSION IN PROFESSIONAL FOOTBALL
}

FORMACIÓN DE JUGADORES EN CLUBES DE UNA CIUDAD DEL INTERIOR DE RIO GRANDE DO SUL (RS): CIRCULACIÓN, ESCOLARIZACIÓN E INSERCIÓN EN EL FÚTBOL PROFESIONAL

\author{
Luiz Carlos Rigo*, Daniel Vidinha da Silva*, Carmen Silvia de Moraes Rial**
}

\begin{abstract}
Palavras chave:
Futebol.

Educação

continuada.

Ocupações.

Antropologia

Cultural.

Resumo: Este artigo tratou da formação de jogadores de futebol. O corpus empírico do estudo constitui-se de cinco clubes da cidade de Pelotas, Rio Grande do Sul, Brasil. Os objetivos principais trataram do processo de formação dos jogadores, mais especificamente a procedência, a circulação, a escolarização e a inserção no futebol profissional. A metodologia utilizada foi a etnografia com o apoio da netnografia. A pesquisa identificou que aproximadamente metade dos jogadores procedia de outras cidades, 22 de um total de 84 estavam com os estudos interrompidos e muitos apresentavam defasagem escolar. Catorze futebolistas (de 84) conseguiram firmar contrato profissional após ultrapassar a idade das categorias de base de seus respectivos clubes. Concluiu-se que a grande maioria dos futebolistas passa por um processo de circulação que dificulta a possibilidade de conciliar formação futebolística com escolarização.
\end{abstract}

Keywords:

Soccer.

Education,

continuing.

Occupations.

Cultural

Anthropology.

Palabras clave:

Fútbol.

Educación Continua.

Ocupaciones.

Antropología

Cultural.

\begin{abstract}
This article approached formation of football players. The empirical corpus were five clubs from the city of Pelotas, Rio Grande do Sul, Brazil. It looks into the process of players' formation, more specifically their origin, circulation, schooling and inclusion in professional football. The methodology applied was ethnographic aided by netnography. The research showed that about $50 \%$ of all players came from other cities; 22 out of 84 (total) had stopped going to school and many were already lagging behind in their studies. Fourteen players managed to sign professional contracts after leaving the junior leagues in their teams. The vast majority undergo a circulation process that hinders their possibility for reconciling sport and school.
\end{abstract}

Resumen: Este artículo trata de la formación de jugadores de fútbol. El corpus empírico se constituye de cinco clubes de la ciudad de Pelotas, RS, Brasil. Los objetivos fueron el proceso de formación de los jugadores, más específicamente la procedencia, la circulación, la escolarización y la inserción en el fútbol profesional. La metodología utilizada fue la etnografía, con el apoyo de la netnografía. La investigación identificó que aproximadamente la mitad de los jugadores procedían de otras ciudades, que 22 de un total de 84 estaban con los estudios interrumpidos y que muchos presentaban desfase escolar. Catorce futbolistas (de 84) lograron firmar contrato profesional después de pasar la edad de las categorías de base de sus respectivos clubes. Se concluyó que la gran mayoría de los futbolistas pasa por un proceso de circulación que dificulta la posibilidad de conciliar la formación futbolística con la escolarización.
*Universidade Federal de Pelotas. Pelotas, RS, Brasil. E-mail: rigoluizcarlos@gmail.com; daniel.ef@hotmail.com.br

**Universidade Federal de Santa Catarina. Florianópolis, SC, Brasil. E-mail: carmenrial2@gmail.com

Recebido em: 26-04-2017 Aprovado em: 12-09-2017

DOI http://dx.doi.org/10.22456/1982-8918.71790

\section{(c) (1) 근 Licence}




\section{INTRODUÇÃO}

Nas últimas décadas, a formação de jogadores de futebol ganhou visibilidade internacional. No Brasil, também houve um aumento do interesse tanto de parte dos clubes como de parte dos profissionais que estão envolvidos com esse tema. ${ }^{1}$ Ao longo do processo de formação os jogadores enfrentam uma série de tensionamentos, como o medo do desligamento do clube, a rotina estafante de treinos, o isolamento social e a incerteza do sucesso na carreira (SOUZA et al., 2008; BARBANTI, 2005).Além disso, com algumas raras exceções, a maioria dos clubes brasileiros oferece uma estrutura e uma equipe de recursos humanos muito inferiores às que são oferecidas pelos clubes europeus para atuar na formação desses jogadores.

Além da falta de políticas clubísticas qualificadas, Carravetta (2012) reclama que no Brasil o processo de formação leva a uma grande circulação dos jovens jogadores, 0 quedificulta a instituição de uma formação futebolística conciliada com a escolarização. A circulação interfere no processo de escolarização e compromete a reconversão profissional ${ }^{2}$, no momento que os jogadores deixam o universo do futebol.

Damo (2005) e Giglio e Spaggiari (2010) assinalam que ainda há uma carência de um número maior de pesquisas referente a este assunto, principalmente de estudos que se preocupem coma complexidade e as diversidades que este tema adquire no contexto do futebol brasileiro. Desse modo, o artigo buscou responder parte dessa carência, tendo como originalidade a investigação do processo de formação de futebolistas no interior do estado do Rio Grande do Sul. Atletas que no ano de 2013 constituíam a categoria de base mais elevada (juvenil ou júnior) de cincos clubes da cidade de Pelotas/RS ${ }^{3}$.

Os principais objetivos da pesquisa foram: identificar a procedência e a circulação desses jogadores, mapear a inserção desses jogadores no futebol profissional e diagnosticar e analisar questões referentes ao processo de escolarização desses jogadores.

\section{OPÇÕES METODOLÓGICAS}

\subsection{A opção pela etnografia}

A pesquisa optou por uma abordagem metodológica qualitativa inspirada na etnografia. Fonseca (1998) destaca que "[...] ponto de partida desse método (etnográfico) é a interação entre o pesquisador e seus objetos de estudo" (FONSECA, 1998, p.58). Magnani (2009) salienta que essa metodologia nos abre a "[...] possibilidade de buscar um ponto de vista descentrado [...]", e acrescenta que "[...] a etnografia é uma forma especial de operar em que o pesquisador entra em contato com o universo dos pesquisados e compartilha seu horizonte" (MAGNANI, 2009, p.135).

Todavia, Geertz (1989) lembra-nos que o que tentamos nos apropriar "[...] não é o discurso social bruto [...]" ao qual não temos acesso direto, "[...] mas apenas àquela pequena

1 Um exemplo disso pode ser identificado na série de reportagens do programa dominical da Rede Globo Esporte Espetacular, intitulada "A Base", exibida em quatro programas em dezembro de 2014 (NATANAEL et al., 2014).

$2 \mathrm{~A}$ reconversão profissional será tratada neste estudo como o processo de busca de uma outra perspectiva profissional para aqueles que não conseguem se consolidar como futebolistas.

3 Pelotas é uma cidade situada na zona sul do Rio Grande do Sul com uma população de aproximadamente 350 mil habitantes. Além de ser uma cidade de destaque na historiografia do futebol brasileiro (RIGO, 2004), nos últimos anos a região revelou inúmeros jogadores conhecidos 
parte dele que nossos informantes nos podem levar a compreender" (GEERTZ, 1989, p. 30). Assim, ao cruzarmos os dados oriundos do corpus empírico com a fundamentação teórica tecemos algumas particularidades, minúcias, detalhes, "esquisitices"(GEERTZ, 1989, p.55), que nos ajudaram a interpretar algumas singularidades dos nativos da bola, mais especificamente dos indivíduos inseridos no universo das categorias de base dos cinco clubes investigados.

A etnografia, metodologia que surge com os estudos antropológicos de observação direta, em pequenas comunidades, e posteriormente é aplicada também em estudos de grupos urbanos, nos últimos anos ampliou seu alcance e vem sendo utilizada também em pesquisas em que não há interações face a face entre pesquisador/pesquisados. Rial (2004), por exemplo, realizou estudo de etnografia de tela, "[...] uma metodologia que transporta para o estudo do texto da mídia procedimentos próprios da pesquisa antropológica [...] da crítica cinematográfica [...] e outras próprias da análise de discurso" (RIAL, 2004, p. 30-31).

Para acompanharmos a migração dos jogadores para outros clubes utilizamos o auxílio do Facebook. Tratou-se somente do uso de um instrumento auxiliar (Facebook), sem, no entanto, ter a intenção de fazer uma pesquisa netnográfica. ${ }^{4}$

\subsection{Logística de campo do estudo - os caminhos percorridos}

para a realização desta pesquisa foram selecionados cinco clubes da cidade de Pelotas. Desses, três possuem equipe profissional e dois são clubes formadores de futebolistas homens, que no momento da pesquisa não possuíam equipes profissionais. A delimitação empírica restringiu-se, especificamente, à última categoria de base em cada clube investigado, em alguns clubes a categoria juvenil (15 a 17 anos) e em outros acategoriajúnior (18 a 20 anos) $)^{5}$. A escolha por essas categorias deu-se, sobretudo, por um dos objetivos da pesquisa ser a investigação do processo de inserção ou não desses jogadores no futebol profissional. Além disso, como lembra Damo (2005, p. 268): "[...] é a partir dos juvenis que os investimentos se intensificam e também onde ocorre o maior número de dispensas".

O primeiro passo (setembro 2013) foi estabelecer uma rede de contatos com alguns indivíduos de cada um dos clubes e com os futebolistas. A seguir foi aplicado um questionário aos coordenadores das categorias de base de cada clube, que abordou questões referentes aos recursos humanos, à infraestrutura e aos aspectos de gestãodos clubes. Nos três últimos meses de 2013, foi feito um cadastramento de um total de 124 adolescentes. Nesse cadastro foram registradas informações referentes à procedência, à naturalidade, à relação que mantinham ou não com empresários do futebol, às condições de moradia e aos seus respectivos graus de escolaridade. Posteriormente, através do Facebook,configuramos uma rede de contatos com eles. Por meio deste instrumento acompanhamos a situação desses futebolistas um ano depois.

Entre os meses de setembro de 2013 e outubro de 2014 realizamos uma série de observações que compuseram nossos diários de campo. As visitas ocorreram com uma média de três vezes por semana e abarcaram os cinco clubes investigados. Além das observações

4 A netnografia pode ser definida como uma etnografia de tela, centrada nos conteúdos disponibilizados através da internet (AMARAL et al., 2008; RECUERO, 2009; LIMA, 2010).

5 Os cincos clubes que constituíram o corpus empírico para esta pesquisa foram: Grêmio Esportivo Brasil (categoria júnior), Esporte Clube Pelotas (categoria juvenil), Grêmio Atlético Farroupilha (categoria juvenil), Fragata Futebol Clube (categoria juvenil) e Progresso Futebol Clube (categoria juvenil). Entre os indicativos da tradição que estes clubes possuem na formação de jogadores no estado, está a conquista alcançada pelo Progresso Futebol Clube (Rubro Negro Pelotense) ao vencer por 3 a 1 o Sport Club Internacional no Estádio Beira-Rio e conquistar 0 título de Campeão Estadual na categoria Sub-17 de 2016 (GUERREIRO, 2016). 
também consultamos os registros existentes nos clubes (contratos e fichas cadastrais) e realizamos conversas informais com jogadores e com outros profissionais ligados aos clubes. Assim, procuramos preservar as particularidades e especificidades para então lançar-nos às generalizações (GEERTZ, 1989).

Durante o período em que estivemos no campo, além das observações,com conversas informais,também realizamos dez entrevistas semiestruturadas que foram previamente agendadas: foram entrevistados quatro coordenadores das categorias de base, um dirigente, quatro atletas e uma pedagoga. Os jogadores foram entrevistados aproximadamente um ano após termos realizado o cadastramento e foram selecionados por representarem diferentes situações futebolísticas. No sentido de termos um maior cuidado ético, optamos por utilizar nomes fictícios e preservar a identidade dos entrevistados ${ }^{6}$.

Um ano após o cadastramento foi aplicado um questionário com o objetivo de diagnosticar a situação dos entrevistados. Este instrumento foi encaminhado aos 124 jogadores cadastrados na pesquisa através de mensagens instantâneas via Facebook. Ao final da coleta obtivemos o retorno de 84 questionários.

Essa gama de dados empíricos de natureza distinta constituiu o suporte empírico que utilizamos para praticarmos uma etnografia. Como lembra Clifford Geertz (1989, p. 4):"[...] praticar a etnografia é estabelecer relações, selecionar informantes, transcrever textos, levantar genealogias, mapear campos, manter um diário, e assim por diante". Todavia, o próprio autor alerta que esses e outros procedimentos metodológicos são ferramentas, no entanto, o que define a qualidade do empreendimento é o uso que cada pesquisador faz dessas ferramentas.Desse modo, fazer etnografia é como tentar ler "[...] um manuscrito estranho" (GEERTZ, 1989,p. 7) 7 .

\section{INSERÇÃO OU RECONVERSÃO}

\subsection{Procedência, captação, formação, circulação e escolarização}

No universo futebolístico é comum a utilização dos termos "captar" e "formar jogadores". Apesar de ambos referirem-se à presença deles no "sistema futebolístico" ${ }^{8}$, eles designam diferentes situações. Desse modo, o termo captação foi utilizado para nos referirmos à modalidade de inserção dos jogadores nos clubes, independentemente de eles serem provenientes de outros clubes de futebol, do futsal ou da várzea. E o termo formação foi usado para tratar do processo pelo qual esses jogadores passam no decorrer de suas carreiras, especialmente antes de se profissionalizarem.

Damo (2005) e Spaggiari(2015) utilizam o conceito de "produção" de jogadores, ao invés de formação. Todavia, guardadas certas especificidades e cuidados teóricos, especificamente nesse estudo, produção e formação podem ser considerados conceitos similares, pois ambos

6 No decorrer do artigo as passagens oriundas de fontesoraisforam citadas de duas maneiras distintas: como entrevistas, quandoreferem-se a fragmentos de entrevistasplanejadas e previamente agendadas, e comoDiário de Campo (DC), quandoreferem-se ao uso de fragmentos de falas coletados junto às observações de campo, sem agendamento prévio. Todavia, ambas consistem em ferramentas do trabalho de campo utilizado para praticar uma etnografia.

7 A fim de atender aos procedimentos e cuidados éticos, esta pesquisa foi submetida ao Comitê de Ética em Pesquisa na Escola Superior de Educação Física da Universidade Federal de Pelotas (CEP-ESEF-UFPel) e aprovada sob o parecer nº 521.976.

8 No artigo intitulado "Rodar" (2008), Carmen Rial trabalha o conceito de "sistema futebolístico". A autora toma como referência o conceito de "campo" de Bourdieu e conceitua o "sistema futebolístico" como um campo mais amplo, que engloba o "campo futebolístico" propriamente

dito, o "campo jornalístico" e o "campo econômico". 
se referem ao trabalho com jovens futebolistas com perspectivas de profissionalização. Desse modo, a opção pelo conceito de formação deu-se, principalmente, por este ter sido o termo mais utilizado pelos jogadores e pelos demais profissionais com quem convivemos na pesquisa de campo.

No levantamento que realizamos, dos 124 jogadores cadastrados, 63 eram naturais de Pelotas e 61 de outras cidades, alguns de fora do estado. ${ }^{9}$ Os jogadores cadastrados na pesquisa chegaram aos clubes por meio da indicação de empresários, de dirigentes, de treinadores, de olheiros ou eram procedentes das escolinhas dos próprios clubes. Isso mostra que as tradicionais peneiras vêm se transformando mais em uma estratégia de marketing dos clubes do que em um momento de captação de futuros jogadores. No entanto, um ou outro ainda consegue ingressar em algum clube via peneira, principalmente se tiver idade inferior a 16 anos (BITTENCOURT, 2009; BACK, 2005; DAMO, 2005; RODRIGUES, 2003; SPAGGIARI, 2009).

Após a captação, começa o processo de formação, constituída por treinamentos intensos, pouca remuneração, longos confinamentos, muita disciplina, demanda emocional e corporal, circulação ${ }^{10}$, angústias, possibilidade de exclusão e de dispensa do clube, etc. A participação em competições foi outro componente lembrado como algo fundamental na formação do jogador. Moisés, coordenador de categorias de base, destacou que "[...] tu forma a partir do que tu compete, então ele tem que jogar competições de nível" (Moisés).

Sobre a circulação (o rodar), raros foram os jogadores que permaneceram mais de três anos no mesmo clube, em média eles já haviam passado por três clubes, mas, entre os jogadores que compuseram nossa pesquisa, chamou a atenção o fato de um jogador já ter "rodado" por 11 clubes $^{11}$. Sobre os efeitos dessa lógica na formação dos jogadores,nossos entrevistados expuseram algumas controvérsias. Se por um lado ela pode ajudar o jogador a "amadurecer" (Jeremias), dar maior "experiência para o cara" (Pedro), por outro lado, ela pode trazer uma série de dificuldades ao futebolista.

Tomamos como exemplo o caso de Ezequiel (19 anos, natural de Curitiba/Paraná). Agenciado por um empresário desde os 13 anos, Ezequiel começou sua formação no São Paulo Futebol Clube/SP e em 2014 já havia passado por outros dez clubes, inclusive por alguns clubes renomados, como Olympique de Marselha (França), Deportivo La Coruña (Espanha), Boavista (Portugal), Grêmio FootBall Porto Alegrense, de Porto Alegre/RS, Coritiba FootBall Club/PR. Na maioria desses clubes, Ezequiel não permaneceu por mais de seis meses. Ao ser solicitado para falar sobre os efeitos disso em sua carreira ele respondeu que "[...] depende do ponto de vista". E acrescentou que, no seu caso, se tivesse circulado menos "[...]seria melhor"12.

A ausência de um planejamento continuo de médio e longo prazo dos clubes brasileiros contribui para acelerar e anteciparo processo de circulação e migração de jogadores, tanto entre diferentes clubes nacionais como para o exterior, produzindo uma "crescente juvenilização"

\footnotetext{
9 Os atletas de outros estados eram procedentes de São Paulo, Paraná, Alagoas, Bahia e Maranhão. Os jogadores de outras cidades do RS eram naturais de municípios próximos a Pelotas (Capão do Leão, Rio Grande, Canguçu, Pinheiro Machado, Pedro Osório, Jaguarão e Piratini), o que permitia o translado diário entre clube e residência.

10 Rodar é o termo usado pelos futebolistas para se referir ao processo de circulação entre clubes (RIAL, 2008).

11 Caso de nosso informante Ademir, que no ano da realização desta pesquisa estava com dezoito anos e já havia passado pelos seguintes clubes: Clube de Regatas Flamengo (RJ), Fluminense Football Club (RJ), Esporte Clube Bahia (BA), América Futebol Clube (MG), Ipatinga Futebol Clube (MG), Clube Atlético Juventus (SP), Marília Atlético Clube (SP), Guaratinguetá Futebol (SP), Associação Chapecoense de Futebol (SC), Ituano Futebol Clube (SP) e Maringá Futebol Clube (PR). 
(RIAL, 2008) desse fenômeno. Em parte, isso ocorre porque predomina no sistema futebolístico brasileiro um afã para inserir esses jogadores no mercado, fazendo com que a circulação se torne "a ordem" (BITTENCOURT, 2009, p. 179).Vários clubes simplesmente dispensam seus jovens futebolistas quando estes atingem a idade limite da última categoria de base do clube.

Apesar da cidade de Pelotas ser um polo regional na formação de futebolistas, os cinco clubes que investigamos não apresentaram uma proposta com planejamento de médio e de longo prazo para as suas categorias de base.Em 2013, o GE Brasil possuía as categorias sub-11/13/15 e sub-20, mas não possuía a categoria sub-17; Fragata FC, Progresso FC, EC Pelotas e GA Farroupilha possuíam as categorias que abarcavam jogadores entre 13 e 17 anos. No entanto, não possuíam equipes na categoria sub-20. No ano seguinte (2014) o EC Pelotas reativou a sua categoria sub-20, mas o GE Brasil e o GA Farroupilha simplesmente fecharam seus departamentos de base.

\subsection{Escolaridade}

Soares (2011), Damo (2005) e Marques e Samulski (2009) relatam que ao longo do processo formativo os futebolistas dedicam mais de 5.000 horas a treinos e jogos. Os jogadores que investigamos tinham em torno de 16 horas semanais de treinos, mais o tempo do deslocamento para os treinos e para as viagens dos jogos. 0 grande tempo dedicado ao futebol, junto aos desgastes oriundos dos treinos físico,do envolvimento psicológico e emocional, etc., faz com que o futebol interfira no processo de escolarização dos jogadores.

A seguir apresentamos alguns dados referentes ao processo de escolarização dos futebolistas que fizeram parte da pesquisa. Dos 84 jogadores que retornaram o questionário no ano de 2014, 14 ainda estavam cursando o ensino fundamental - desses, seis tinham entre 15 e 16 anos e oito entre 17 e 18 anos. Outros 48 estavam frequentando o ensino médio (12 com idades entre 15 e 16 anos; 27entre 17 e 18 anos e nove com 19 ou 20 anos). Doze haviam concluído o ensino médio, quatro estavam cursando o ensino técnico e seis o ensino superior.

Esses dados indicam que um grande número dos futebolistas apresentava uma significativa defasagem escolar. Além disso, dos 84 futebolistas que retornaram o questionário, 22 haviam interrompido os seus estudos. Desses, quatro estavam cursando o ensino fundamental e nove o ensino médio. Ao comentarem sobre essa interrupção, alguns disseram que pretendiam retomar os estudos, outros, por sua vez, não explicitaram expectativa ou vontade de fazer isso.

Entre as principais dificuldades para a compatibilização da escolarização com o futebol, nossos entrevistados destacaram as viagens, os treinos, o cansaço e as constantes trocas de cidades. Jeremias, por exemplo, enfatizou que: "[...] com a rotina de treinos o estudo fica um pouco mais difícil e, às vezes, tens que faltar a aula por causa de viagem". E, acrescentou: "[...] eu gosto de estudar, mas meu primeiro plano sempre foi jogar futebol". Isaías, outro futebolista, ressaltou que "[...] a maioria dos jogadores não rodam de ano porque são burros, eles reprovam porque circulam, trocam de clube e de cidade" (DIÁRIO DE CAMPO, 24 set. 2014). Em um estudo com garotos de clubes da Série A do Campeonato Brasileiro, Marques e Samulski (2009) diagnosticaram que 53\% dos futebolistas possuíam alguma defasagem nos níveis de escolaridade. 
Contudo, apesar da interferência que o futebol produz no processo de escolarização, cabe a ressalva de que, independentemente do futebol, em nosso país a escolarização dos jovens das classes populares ainda é um desafio a ser alcançado. Nesse sentido, Mello (2010) alerta-nos para não tomarmos como verdade generalizável a ideia "[...] socialmente partilhada no Brasil que o futebol retira os jovens do sistema escolar" (MELLO, 2010, p. 24). Além disso, os dados desta pesquisa não nos possibilitam aferir tratar-se de um processo de escolaridade muito diferente do predominante entre os jovens das classes sociais de que provém a maioria dos futebolistas.

Ao tratar desse tema, Soares et al. (2011) lembram que para conciliar estudo e futebol é necessário certo sacrifício. No entanto, logo que há qualquer sinal de sucesso no futebol, os estudos tendem a ser deixados de lado. Um indicador disso é "[...] deslocamento dos atletas para o ensino noturno" (SOARES, et al., 2011, p. 915). Esse deslocamento acentua-se mais a partir da categoria sub-20 (MELO, 2010).

O distanciamento dos familiares, enfatizado pelo processo de circulação, também contribui para o insucesso escolar, pois a família representa um importante suporte econômicoe emocional, principalmente no estágio inicial da carreira de um jogador (DA COSTA et al., 2010). Sobre isso, Rial (2008) destaca que apesar da formação do jogador começar no seio familiar, logo agregam-se empresários, treinadores, dirigentes e outros agentes, reforçando a ideia do jogador como um investimento lucrativo.

Preocupada com as dificuldades que envolvem o desafio de conciliar estudo e formação futebolística, a pedagoga Maria ressaltou que o mais indicado "[...] seria haver um trabalho multidisciplinar"13.

Moisés (coordenador) alertou para a falta de "[...] uma política de governo que monitore os alunos e os clubes". Preocupação similar às assinaladas por Melo (2010) e por Damo (2005). Ao se referir ao sistema de produção/formação dos jovens futebolistas brasileiros, Damo (2005) denuncia que, além de não haver "uma formação complementar", apermissibilidade existente facilita para que os jovens futebolistas brasileiros sejam "desterritorializados segundo as estratégias de clubes e agentes/empresários" (DAMO, 2005, p. 110). Na mesma linha, Moisés ressalta que, inclusive: "[...] pode-se matricular e tirar os alunos em meio ao período escolar" (DIÁRIO DE CAMPO, 21 jul.2014).

\subsection{Inserção no futebol profissional}

Diferentemente damaioria das outras carreiras, a possibilidade de profissionalização no futebol tende a ocorrer mais cedo, pois "[...] à medida que o tempo passa, a entrada no mercado do futebol deespetáculo se torna mais difícil" (SOUZA et al., 2009, p. 107).

Ao analisar sete clubes da primeira divisão do futebol brasileiro, Paoli (2007) observou que girava em torno de 5 a10 \% o percentual de jogadores da categoria sub-20 que passavam para a profissional. Em âmbito nacional menos de $3 \%$ dos garotos que iniciam no futebol concretizam seus sonhos de "[...] ser jogador de futebol" (PIMENTA, 2000, p.32). Nesse processo, as categorias juvenil e juniores singularizam-se por se caracterizar como"rito de passagem" (SOUZA, 2008, p.79) para a profissionalização. 
Dos 84 jogadores que retornaram o nosso questionário final da pesquisa, 14 assinaram o seu primeiro contrato profissional em 2014. Os dados que coletamos mostraram também que, desses 84, em 2014, 46 continuavam com vínculos clubísticos, enquanto 37 não. Dos que estavam sem vínculos com clubes, 15 responderam que pretendiam abandonar o futebol e os outros 22 informaram que iriam continuar insistindo mais um pouco. Entre os 46 que estavam com vínculos, 23 permaneciam no mesmo clube do ano anterior (2013), 12 mudaram para outros clubes da própria cidade (Pelotas) e 11 haviam migrado para clubes de outras cidades (um para Lajeado/RS, dois para Santa Maria/RS, dois para Porto Alegre/RS, um para Igrejinha/ RS, um para Santo Ângelo/RS, um para São Leopoldo/RS, um para Florianópolis/SC, um para Pato Branco/PR e um para Rancagua/Chile).

Apesar do Fragata e do Progresso serem duas referências regionais na formação de jogadores, entre os 14 atletas que conseguiram se profissionalizar apenas um teve passagem por uma destas agremiações (Fragata). Em parte, isso pode estar relacionado ao fato desses dois clubes não possuírem equipes profissionais, o que obriga os jogadores a terem que buscar outras equipes para se profissionalizar. Além disso, a maioria dos atletas destes clubes (Fragata e Progresso) tinha menos de 18 anos, o que lhes dá um prazo maior para tentarem a inserção no futebol profissional.

A exemplo de outros clubes, conforme assinalou Spessoto (2008), nos últimos anos, os três clubes profissionais da cidade (Brasil, Pelotas e Farroupilha)não têm priorizado a profissionalização de jogadores da base. Sobre essa opção, Moisés destacou que "[...] 0 problema é que os clubes da cidade ainda estão com uma sistemática de trinta, quarenta anos atrás" (MOISÉS, 2014) ${ }^{14}$.

Diferentemente do Brasil, Pelotas e Farroupilha, Progresso e Fragata não possuem equipes profissionais, são clubes "exógenos" (DAMO, 2005), formam jogadores para atender as demandas mercadológicas do sistema futebolístico, "[...] são agremiações organizadas conforme os princípios dos empreendimentos capitalistas" (DAMO, 2005, p. 332). Princípio evidenciado no depoimento de Roberto, quando ele declara que: "[...] de 95 atletas que nós temos hoje, posso te dizer que da safra de 2014 pode sair um atleta só, que pode se tornar jogador de alto nível" (ROBERTO, 2014).

O fim da perspectiva de se tornar jogador profissional é uma realidade dolorida para todos esses adolescentes. A maioria deles resiste e persiste, como é o caso de Jeremias: "[...] talvez seja minha última cartada [a promessa de um empresário], depois, acho que só no Farroupilha que a gente tem contato ali” (JEREMIAS, 2014). Ao trocarmos ideias com o jogador Gabriel, ele comentou que havia vários companheiros seus que estavam "[...] com medo que não seriam encaminhados para nenhum clube. Assim, eles já estão procurando por fora e não estão nem esperando a decisão deles daqui” (DIÁRIO DE CAMPO, 30 set. 2014).

Outra estratégia utilizada para tentar permanecer no futebol são as redes sociais. Nelas os jogadores postam vídeos das suas melhores jogadas, dos gols que fizeram, dos times em que atuaram, reportagens de jornais que os qualificam, etc. Enfim, tentam fazer do espaço virtual um lugar de visibilidade de seus capitais futebolísticos. ${ }^{15}$

\footnotetext{
14 Somados os elencos profissionais do primeiro semestre de 2013 , dos três clubes, identificamos que de um total de 75 atletas, dez eram oriundos da base de clubes da cidade, e sete deles não foram formados pelos mesmos clubes a que estavam vinculados (dados obtidos pessoalmente nos clubes e através de seus sites oficiais).

150 termo "capital futebolístico" consiste em uma apropriação do tratamento que Bourdieu faz ao conceito de capital, mais propriamente, a passagem em que o autor ressalta a existência de um "capital cultural", um "capital social" e um "capital simbólico", além da clássica noção de "capital econômico". No corpo social esses capitais entrecruzam-se e facilmente um pode converter-se em outro (BOURDIEU, 1984; 1992). Considerações mais detalhadas sobre o conceito de "capital futebolístico" ver: Damo (2005).
} 
As redes sociais mais utilizadas pelos jogadores foram o Facebook e o YouTube. Geralmente são eles mesmosque manejam essas ferramentas. O mais comum são as postagens de vídeos com jogadas em que eles se sobressaem e reportagem que enfatizam suas qualidades. Outra estratégia utilizada é a de dar destaque às passagens que tiveram pelos clubes que gozam de um determinado reconhecimento no meio futebolístico. Os registros dessas passagens são mantidos em suas homepages, mesmo após eles não estarem mais vinculados àqueles clubes.

\section{CONCLUSÃO}

Os cinco clubes investigados apresentaram características distintas. Enquanto EC Pelotas, GA Farroupilha e GE Brasil são clubes que vêm priorizando a categoria profissional em detrimento das categorias de base, Fragata FC e Progresso FC são clubes formadores ou "exógenos". Ou seja, instituições voltadas para formar futebolistas para o mercado. Esses dois clubes são os que captam os melhores jogadores da região e também são os que alcançam os melhores resultados entre os clubes da cidade, nas competições de que participam. Entretanto, foi nesses dois clubes que a mercadorização e a exclusão dos jovens futebolistas foram tratadas com maior naturalidade. "Infelizmente o processo é assim. Os que podem ser aproveitados, são. Os demais são liberados pelo clube" (JOSÉ, 2014).

Em relação à circulação nas categorias de base, concluímos que esse é um fenômeno característico do futebol brasileiro que se intensificou e estendeu-se aos clubes do interior, sejam eles formadores ou não. Muitos clubes das capitais e até do exterior vêm instituindo franquias com clubes formadores do interior. Com isso, em troca de um determinado suporte financeiro os grandes clubes adquirem prioridade para com os futebolistas que são formados em outros clubes menores do interior. Se, por um lado, isso pode facilitar o acesso de alguns jogadores a um clube maior, por outro lado, contribui para intensificar o processo de circulação, instituindo um vai e vem dos futebolistas entre os clubes parceiros. $O$ jogador vai para o clube da capital (clube matriz), fica um tempo, se não atende às expectativas é mandado de volta para o clube do interior.

A maioria dos nossos entrevistados concebia a circulação como uma característica da profissão, postura similar à que identificou Rial (2008), ao tratar dos futebolistas brasileiros "transmigrantes ${ }^{16 "}$ que atuavam na Europa. Ou seja, predomina entre os futebolistas brasileiros um entendimento de que "rodar" é parte do ofício. Independentemente de onde atuam, ou da fase profissional em que se encontram, essa ideia pouco muda.Mesmo que mudem, no entanto, as condições de possibilidades das práticas de circulação instituídas pelo sistema futebolístico transnacional.

Sobre a procedência e a naturalidade dos jogadores que fizeram parte do estudo, identificamos que aproximadamente a metade deles não é natural de Pelotas. Afastados de suas famílias, os clubes tornam-se suas principais referências, por isso deveriam assumir uma responsabilidade e um cuidado ainda maior perante a vida e a escolarização desses futebolistas. Todavia, nem sempre isso ocorre. Apesar do esforço feito de parte de alguns clubes, muitos jogadores apresentavam defasagem escolar. Além disso, um número significativo estava com os estudos interrompidos e vários declararam relegar a escolarização a um plano secundário.

16 "Transmigrantes" porque, paralelo aosvínculos que instituem nos países em que jogam, continuam mantendo vínculos sociais, econômicos e afetivos com o Brasil (RIAL, 2008). 
Quanto à reconversão profissional, o estudo identificou que a maioria dos jogadores tende a pensar nela com seriedade somente quando se depara com o drama do insucessona carreira futebolística, o que a torna mais difícil e às vezes dramática. Uma realidade que necessita ser enfrenta e modificada: primeiro porque inúmeros estudos mostram que a grande maioria dos jogadores das categorias de base não consegue consolidar-se como futebolistas profissionais; segundo, porque similar ao que observou Wacquant (2002), ao tratar do capital específico adquiridos pelos boxeadores, também no futebol o capital futebolístico construído ao longo de anos de treinos "[...] fica desprovido de valor em outro campo"(WACQUANT, 2002, p. 79).

Sobre a inserção no futebol profissional, foi possível constatar que apesar de não serem muitos os futebolistas que no ano de 2014 haviam conseguido inserir-se no futebol profissional, o fato de 14 , de um total 84 , terem conseguido assinar seu primeiro contrato profissional indica que os clubes da cidade de Pelotas vêm desempenhando um papel de destaque na formação de novos futebolistas ${ }^{17}$.

Outra particularidade que a pesquisa assinalou foi a de que o destino principal dos futebolistas que conseguiram se profissionalizar foram os clubes do interior do estado do RS. Assim, esses outros clubes do interior, apesar de não serem os sonhos da maioria deles, são a porta de entrada desses jovens futebolistas no disputado e excludente universo do futebol profissional.

Todavia, cabe ressaltar que, ao atingir o limiar de idade das categorias de base dos clubes em que estavam atuando, a grande maioria foi dispensada e teve que correr atrás de outros clubes ou abandonar o futebol. Na esperança de resistir à exclusão do universo futebolístico, os jovens futebolistas recorrem também às redes sociais como um lugar para dar visibilidade a seus capitais futebolísticos.

Além de uma reconfiguração nas políticas clubísticas que incide em melhor planejamento, maior empoderamento das categorias de base, condições mais apropriadas para conciliar formação futebolística e escolarização, a pesquisa mostrou também a necessidade de uma maior interferência governamental. Interferência essa que pode ter como referência os avanços alcançados nesse campo em países como Alemanha, Espanha, Holanda e França. ${ }^{18}$ Países em que os jogadores em formação estão menos expostos a uma grande circulação e, além disso, conseguemuma melhor conciliação entre a formação futebolística e escolarização do que no Brasil. Uma maior escolarização certamente contribui para amenizar as dificuldades presentes em uma possível reconversão profissional, principalmente para aqueles futebolistas que foram excluídos precocemente do universo do futebol profissional.

\section{REFERÊNCIAS}

AMARAL, Adriana; RECUERO, Raquel; MONTARDO, Sandra Portella. Blogs: Mapeando um objeto. In: CONGRESSO NACIONAL DE HISTÓRIA DA MÍDIA, NO GT HISTÓRIA DA MÍDIA DIGITAL, 6., 2008. Anais... Universidade Federal Fluminense, 2008. p. 1-16.

17 Em termos de percentuais o número de jogadores que se profissionalizaram está acima da média nacional (RIAL, 2009; PIMENTA, 2000; PAOLI, 2007). 
BACK, Luciano. Gestão de Custos nas Categorias de Base de um Clube de Futebol Através do Método ABC. 2005.69f. Monografia (Bacharel em Ciências Contábeis) -Universidade Federal de Santa Catarina, Florianópolis, 2005.

BARBANTI, Valdir. Formação de Esportistas. Barueri: Manole, 2005.

BITENCOURT, Fernando Gonçalves. No reino do quero-quero:corpo e máquina, técnica e ciência em um centro de treinamento de futebol - uma etnografia ciborgue do mundo vivido.2009. 332f.Tese (Doutorado em Antropologia Social) - Universidade Federal de Santa Catarina, Florianópolis, 2009.

BOURDIEU, Pierre. Economia das trocas simbólicas. São Paulo: Perspectiva, 1992.

BOURDIEU, Pierre. Questions de sociologie. Paris: LesÉditions de Minuit, 1984.

CARRAVETTA, Élio. Futebol: a formação de times competitivos. Porto Alegre: Sulina, 2012.

DA COSTA; Varley Teoldo et al. Fases de transição da carreira esportiva: perspectiva de exatletas profissionais do futebol brasileiro. Conexões: revista da Faculdade de Educação Física da UNICAMP, v. 8, n. 3, p. 84-103, set./dez. 2010.

DAMO, ArleiSander. Do Dom à Profissão:Uma Etnografia do Futebol de Espetáculo a Partir de Jogadores no Brasil e na França. 2005. 435f.Tese (Doutorado em Antropologia Social) -Universidade Federal do Rio Grande do Sul. Porto Alegre, 2005.

FONSECA, Cláudia. Quando cada caso não é um caso: pesquisa etnográfica e educação. In: REUNIÃO ANUAL DA ANPED, 21.1998. Anais... Universidade Federal do Rio Grande do Sul, 1998. n.10, p. $58-78$.

GEERTZ, Clifford. A Interpretação das Culturas. Rio de Janeiro: Afiliada, 1989.

GIGLIO, Sérgio; SPAGGIARI, Enrico. A produção das ciências humanas sobre futebol no Brasil: um panorama (1990-2009).Revista de História, n. 163, p. 293-350, jul./dez. 2010.

GUERREIRO, Vinicius. Progresso vence campeonato estadual sub-17.Jornal Diário Popular, Pelotas, 20 nov. 2016. Caderno Esportes. Disponível em: <http://www.diariopopular.com.br/index. php?n sistema=3056\&id noticia=MTE5MTcz\&id area=Mw>.Acesso em: 21 nov. 2017.

LIMA, Letícia Salem Herrmann. O jovem e a sua relação com orkut. socialização, informação, afeto e imaginação. Revista Eletrônica [da] Faculdade Cásper Líbero. v. 2, n. 1. p. 1 - 15. jun. 2010.

MAGNANI, José Guilherme Cantor.Etnografia como prática e experiência.Horizontes Antropológicos, v. 15, n. 32, p. 129-156, jul./dez. 2009.

MARQUES, Maurício Pimenta; SAMULSKI, Dietmar Martin. Análise da carreira esportiva de jovens atletas de futebol na transição da fase amadora para a fase profissional: escolaridade, iniciação, contexto sócio-familiar e planejamento da carreira. Revista Brasileira de Educação Física e Esporte, v.23, n.2, p.103-119, abr./jun. 2009.

MELO, Leonardo Bernardes Silva de. Formação e escolarização de jogadores de futebol no Estado do Rio de Janeiro.2010. 72f. Dissertação (Mestrado em Educação Física) Universidade Gama Filho, Rio deJaneiro, 2010.

NATANAEL, Rubian; FARIA, Eric; VAN DER LAARS, Guilherme. "A base, da terra à grama": nova série mostra a formação do jogador brasileiro. Disponível em: <http://globoesporte. globo.com/programas/esporte-espetacular/noticia/2014/10/base-da-terra-grama-nova-serie-mostraformacao-do-futebol-brasileiro.html>. Acesso em: 18 dez. 2016. 
PAOLI, Próspero Brum. Os estilos de futebol e os processos de seleção e detecção de talentos. 2007.187f. Tese (Doutorado em Educação Física) -Universidade Gama Filho, Rio de Janeiro, 2007.

PIMENTA, Carlos Alberto Maximo. Novos Processos de Formação de Jogadores de Futebol e o Fenômeno das "escolinhas": uma análise crítica do possível.In: Peligro de Gol. Estudios sobre deporte y sociedad en América Latina.Buenos Aires: CLACSO, 2000. p. 75 - 97.

RECUERO, Raquel. Redes Sociais na Internet.Porto Alegre. Sulina, 2009.

RIAL, Carmen. "Porque todos os 'rebeldes' falam português": a circulação de jogadores brasileiros/sul-americanos na Europa, ontem e hoje. Antropologia em primeira mão,n.110, p. 1-22, 2009.

RIAL, Carmen. Mídia e sexualidades: breve panorama dos estudos de mídia.In: GROSSI, M. et al.(Org.). Movimentos sociais, educação e sexualidades. Rio de Janeiro: Garamond, 2004.p. 107-136.

RIAL, Carmen. Rodar: A Circulação dos Jogadores de Futebol Brasileiro no Exterior. Horizontes Antropológicos, v. 14, n.30, p.21-65, jul./dez. 2008.

RIGO, Luiz Carlos. Memórias de um Futebol de Fronteira. Pelotas: Editora Universitária UFPel, 2004.

RODRIGUES, Francisco Xavier Freire. A Formação do Jogador de Futebol no Sport Club Internacional (1997-2002). 2003. 200f. Dissertação (Mestrado em Sociologia) - Universidade Federal do Rio Grande do Sul, Porto Alegre, 2003.

SOARES, Antônio Jorge Gonçalveset al. Jogadores de futebol no Brasil: mercado, formação de atletas e escola. Revista Brasileira de Ciências do Esporte, v. 33, n. 4, p. 905-921, out./dez. 2011.

SOUZA, Camilo Araújo Máximo de et al. Difícil Reconversão: futebol, projeto e destino em meninos brasileiros. Horizontes Antropológicos, v. 14, n.30, p.85-111, jul./dez. 2008.

SOUZA, Júlio César Couto de. A transformação do futebol brasileiro: avanços e recuos na sua modernização e repercussões nas categorias de base. 2001. 157 f. Dissertação (Mestrado em Educação Física) - Universidade Federal de Santa Catarina, Florianópolis, 2001.

SPAGGIARI, Enrico. Família joga bola: constituição de jovens futebolistas na várzea paulistana. Anode defesa. 470f. Tese (Doutorado em Antropologia Social). Universidade de São Paulo, 2015.

SPAGGIARI, Enrico.Tem que ter categoria:construção do saber futebolístico. Ano de defesa. 265f.Dissertação (Mestrado em Antropologia Social) - Universidade de São Paulo. São Paulo, 2009.

SPESSOTO, Rubens Eduardo Nascimento. Futebol Profissional e Administração Profissional:da prática amadorista à gestão competitiva. 2008. 141f. Dissertação (Mestrado em Educação Física) - Universidade de Brasília, Brasília, 2008.

WACQUANT, Löic.Corpo e Alma:Notas Etnográficas de um Aprendiz de Boxe. Rio de Janeiro: Relume Dumará, 2002.

\section{Apoio financeiro:}

